\title{
S-Adenosyl-L-Methionine Ameliorates Reduced Local Cerebral Glucose Utilization Following Brain Ischemia in the Rat
}

\author{
Kazuo KOBAYASHI, Eiichi NAKAJIMA', Yoshiko KUBO, \\ Yoshie YASUKAWA ${ }^{1}$ and Nobuyoshi IWATA* \\ Biological Research Laboratories. 'Analytical and Metabolic Research Laboratories, \\ Sankyo Co., Ltd., Hiromachi 1-2-58, Shinagawa-ku, Tokyo 140, Japan
}

Accepted October 2, 1989

\begin{abstract}
The average values of the local cerebral glucose utilization (LCGU) were approx. $35-110 \mu \mathrm{mol} / 100 \mathrm{~g} / \mathrm{min}$ in various nuclei in the brain of shamoperated animals. The values, however, were decreased by $25-75 \%$ in all areas examined at $24 \mathrm{hr}$ after 4-vessel occlusion (forebrain ischemia) for $0.5 \mathrm{hr}$. Particularly, the LCGU values in the forebrain nuclei such as the cerebral cortices and thalamus were severely reduced. while that in the nuclei in the midbrain and hindbrain such as the red nucleus, chochlear nucleus and vestibular nucleus were slightly reduced. In rats treated with S-adenosyl-L-methionine (SAM, $100 \mathrm{mg} / \mathrm{kg}$. i.p.) every $1 \mathrm{hr}$ for 6 times from the recirculation, however, the LCGU values were increased in all brain structures by $35-195 \%$ in the forebrain ischemic rat. A significant increase was observed in the cerebral neocortices, caudate-putamen, lateral septal nucleus, thalamic nuclei, substantia nigra, cerebellum and some other nuclei. In some forebrain structures whose LCGU were mildly reduced to approx. 60-70\% by the ischemia, SAM recovered the LCGU to more than $90 \%$ of the value in the sham-operated group. Thus it was concluded that SAM ameliorated widely ischemia-induced reduction of LCGU in the rat.
\end{abstract}

It has been well-known that numerous cerebral metabolisms. such as metabolisms of glucose, high energy phosphates and monoamines, were disturbed and $\mathrm{Ca}$ flowed into the cell during and following brain ischemia (1. 2). These pathological changes are thought to result in neuronal death and severe brain damages.

$S$-Adenosyl-L-methionine is involved in the biosynthesis of membrane phospholipids (3) and in monoamine metabolism (4) as a methyl donor, and it is a!so concerned with $\mathrm{Ca}$ efflux from the cel! (5). Although S-adenosylL-methionine was unstable itself, its stable salt, $\quad S$-adenosyl- $L$-methionine- 2 - sulfate tosylate (SAM) was developed by Fiecchi (6), so the various effects of SAM upon cerebral ischemia could be elucidated. It has been reported that systemically administered SAM suppressed development of brain edema (7.

\footnotetext{
* To whom reprint requests should be addressed.
}

8). improved cerebral glucose and energy metabolisms (8, 9), prevented neurons from delayed death in the CAl sector of the hippocampus $(10,11)$ and increased survival time (7. 12). In addition, SAM showed some clinical improvements in neurological symptoms when it was administered to patients in the acute phase of cerebrovascular disorders (13).

On the other hand, Sokoloff et al. (14) developed the method for estimation of local cerebral glucose utilization (LCGU) using 2$\left[{ }^{14} \mathrm{C}\right]$-deoxyglucose $\left(2-\left[{ }^{14} \mathrm{C}\right]-\mathrm{dG}\right)$ to assess local neurona! activity biochemically. It was found that the rates of LCGU were decreased following cerebral ischemia (15). Thus an attempt was made to study the effects of SAM upon the reduced LCGU following the ischemia in the rat.

\section{Materials and Methods}

Animal preparation: Male Wistar rats (10weeks-old, Japan Clea) were used after they 
were housed for at least 1 week under contro!led conditions of light. temperature and humidity.

Brain ischemia was produced by the method of Pulsinelli and Brierly (16) with slight modification. Under anesthesia with pentobarbital sodium $(50 \mathrm{mg} / \mathrm{kg}$. i.p. Nembutal, Abbot Lab.), bilateral vertebral arteries of the rat including those of the sham-operated group were electrocauterized. Then a pair of needle electrodes was inserted through the head skin covering the skull for recording the cortical electroencephalograph (EEG). Bilateral common carotid arteries were exposed, and a pair of threads was placed around both of these arteries for later clamping. The animal whose cortical EEG became flat by occlusion of the arteries for less than $30 \mathrm{sec}$ was selected and was maintained under free access of water but deprivation of food overnight.

On the next day, the animal was anesthetized with $1.5 \%$ halothane in a gas mixture containing $95 \%$ oxygen and $5 \%$ carbon dioxide for exposure of the common carotid arteries. After the anesthesia was discontinued, the arteries were occluded with aneurythm clips for $30 \mathrm{~min}$ (forebrain ischemia) and then reflowed by taking the clips off. Only animals which lost their righting reflex and did not respond to light touch stimuli during the ischemia were used for measurement of LCGU. The same procedure except occlusion of the carotid arteries was given to animals in the sham-operated group.

Measurement of LCGU: Ischemia-recirculated rats (ischemic control, $N=6$; drugtreated, $N=5$ ) were anesthesized with $1.5 \%$ halothane at about $20-21 \mathrm{hr}$ after the recirculation. In the sham-operated animals $(N=4)$. the LCGU was similarly determined at approx. the same hour after the operation. A pair of polyethylene catheters was inserted into the femoral artery of one side (for monitoring blood pressure and collecting blood samples) and the vein (for injecting a tracer). After the anesthesia was terminated, the animals were lightly restrained by loose-fitting plaster casts around the lower torso and then were allowed to recover for a minimum of $3 \mathrm{hr}$. The LCGU was measured according to the $2-\left[{ }^{14} \mathrm{C}\right]$ deoxyglucose method of Sokoloff et al. (14). 2 - $\left[{ }^{14} \mathrm{C}\right]$-Deoxyglucose $(100 \mu \mathrm{Ci} / \mathrm{ml} / \mathrm{kg}$, spe- cific activity 50-60 $\mu \mathrm{Ci} / \mathrm{mmol}$, Amersham, 2 $d G)$ was injected intravenously over $15 \mathrm{sec}$. Fifteen timed arterial blood samples were drawn during the next $45 \mathrm{~min}$.

The blood samples were immediately centrifuged, and the plasma was separated to determine the radioactivity and giucose level. An aliquot of plasma sample was dissolved with tissue solubilizer (NCS. Amersham), and $\left[{ }^{14} \mathrm{C}\right]$ levels in the plasma was determined by means of liquid scintillation counting (Packard $200 \mathrm{CA}$ ). Plasma glucose concentrations were determined with a glucose analyzer (Beckman II).

The animal was decapitated at 45 min after injection of $2-d G$. The brain was removed rapidly and was frozen in hexane chilled at $-50^{\circ} \mathrm{C}$. The frozen brain was sectioned coronally $(20 \mu \mathrm{m})$ with a cryostat (American Optics) at $-20^{\circ} \mathrm{C}$. The sections were autoradiographed along with a set of calibrated $\left[{ }^{14} \mathrm{C}\right]$-methylmethacrylate standards (Amersham) on an X-ray film (Kodak SB-5) for 7 days. The optical density of the autoradiogram was measured with a drum-scan densitometer (Optronics, P-1000, 50- $\mu \mathrm{m}$ aperture) controlled by a computer (DEC. PDP 11/34) and an imlage processor (DeAnza, 6400) as described elsewhere (17) and converted into $\left[{ }^{14} \mathrm{C}\right]$ radioactivity. The LCGU was calculated according to an equation described by Sokoloff et al. (14) using values for the rate constants and lumped constant reported for normal rats, as was applied by Pulsinelli et al. to ischemic animals (15).

Physiological variables: Arterial blood $\mathrm{pH}$. $\mathrm{P}_{\mathrm{CO}_{2}}$. $\mathrm{P}_{\mathrm{O}_{2}}$ (Blood $\mathrm{pH}$, gas analyzer, Model 7000. Corning), arterial blood pressure (AP601G, 611G. Nihon Kohden) and hematocrit were determined immediately before $2-\mathrm{dG}$ injection in all groups.

Drug administration: Drug (SAM) which contained $61.5 \%(\mathrm{w} / \mathrm{w}) \mathrm{SAM}$ and $38.5 \%$ $(w / w)$ mannitol as a filler (Fuji Chemical Industry, $100 \mathrm{mg} / \mathrm{kg}$ as S-adenosyl-L-methionine) was dissolved in disodium phosphate $(0.18 \mathrm{M})$, and the $\mathrm{pH}$ of the solution was adjusted to approx. 6.0 with sodium hydroxide. Since S-adenosy!-L-methionine was rapidly metabolized $(18,19)$, SAM was administered (i.p.) repeatedly after the recirculation every $1 \mathrm{hr}$ (in total, 6 times). 
Vehicle (pH adjusted to about 6.0 with sulfuric acid) was similarly administered.

Statistical analysis: The data were expressed as a mean \pm S.E.M. All six physiological variables were statistically compared using Bonferroni's multiple $t$-test (20). The rates of LCGU in 43 individual brain structures in the ischemic control and SAM-treated groups were analyzed by Student's $t$-test. Differences with $P$ values of less than 0.05 were identified to be statistically significant, while those $P$ values were between 0.05 and 0.1 were defined to have a tendency for a significant effect.

\section{Results}

Physiological variables: No statistically significant differences were detected in the arterial $\mathrm{P}_{\mathrm{e}_{2}}$. $\mathrm{P}_{\mathrm{CO}_{2}}, \mathrm{pH}$. hematocrit or blood pressure of the sham-operated, ischemic control and ischemic SAM-treated groups (Table 1 ). The plasma glucose concentration in all 3 groups remained stable throughout the observation period for $45 \mathrm{~min}$.

Ameliorating effects of SAM upon reduced local cerebral glucose utilization: Examples of image-processed autoradiographs of LCGU in the coronal sections from sham-operated. ischemic control and SAM-treated rats are shown in Fig. 1. As summarized in Table 2. the rates of LCGU in the nuclei were about $40-110 \mu \mathrm{mol} / 100 \mathrm{~g} / \mathrm{min}$, and those of the fibers were about $10-30 \mu \mathrm{mol} / 100 \mathrm{~g} / \mathrm{min}$ in sham-operated animals. These values were roughly consistent with that in a similar shamoperated group reported by others (15).

In ischemic control animals, the values of LCGU in the cerebral cortices and the hippocampus were reduced to $40-60 \%$ of the sham-operated group at $24 \mathrm{hr}$ after recirculation following $30 \mathrm{~min}$ forebrain ischemia. A similar depression in the LCGU was observed in other forebrain nuclei or structures such as the hypothalamus, thalamus and neuronal fibers. On the other hand, a less prominent decrease (by about 30-40\%) in LCGU was detected in the midbrain and the hindbrain structures.

On the other hand, in the SAM-treated group, the LCGU values were increased by $35-195 \%$ in all 43 brain regions examined compared with those of the control group. A significant increase was observed in the cerebra! neocortices, caudate-putamen, lateral septal nucleus, thalamic nuclei, substantia nigra, cerebellum and some other nuclei (Table 2, Fig. 1). Particularly, the rates of LCGU were recovered to more than $90 \%$ of the sham-operated group in some forebrain structures such as the piriform cortex, nucleus accumbens, hippocampus, lateral habenular nucleus and subthalamic nucleus, and in most structures in the midbrain as well as the hindbrain, although not significantly.

\section{Discussion}

The 2-deoxyglucose method established by Sokoloff et al. has been widely accepted for estimation of rates of glucose utilization in all of the anatomical and functional components of the brain under physiological conditions (14). It has been reported that rates of glucose utilization in the glia cell-rich region (white matter) were similar to those in the neuron-rich region (basal ganglia) in the human brain (21) or those in the glia cells were rather higher than those in the rat neurons (22). Thus it is clear that glucose is utilized in glia cells as well as in neurons. Although ICGU values in neurons were not separately determined from those in glia cells in the present study. SAM is considered to

Table 1. Physiological variables in arterial blood

\begin{tabular}{lcccccccc}
\hline & $N$ & $\begin{array}{c}\text { Mean blood } \\
\text { pressure } \\
(\mathrm{mmHg})\end{array}$ & Hematocrit & $\begin{array}{c}\text { Blood } \\
\text { glucose } \\
(\mathrm{mg} / \mathrm{dl})\end{array}$ & & $\mathrm{pH}$ & $\begin{array}{c}\mathrm{PCO}_{2} \\
(\mathrm{mmHg})\end{array}$ & $\begin{array}{c}\mathrm{PO}_{2} \\
(\mathrm{mmHg})\end{array}$ \\
\hline Sham Op. & 4 & $133.7 \pm 7.5$ & $55.0 \pm 3.2$ & $232.3 \pm 32.7$ & $7.37 \pm 0.02$ & $47.0 \pm 2.2$ & $113.8 \pm 4.0$ \\
Control & 6 & $135.8 \pm 3.4$ & $48.8 \pm 3.6$ & $241.6 \pm 27.6$ & $7.37 \pm 0.01$ & $47.6 \pm 1.1$ & $124.0 \pm 5.2$ \\
SAM & 5 & $130.8 \pm 4.7$ & $51.4 \pm 3.9$ & $207.4 \pm 18.2$ & $7.26 \pm 0.04$ & $47.8 \pm 2.4$ & $132.6 \pm 4.2$ \\
\hline
\end{tabular}

Values represent the mean \pm S.E.M. of the principal physiological variables measured just before injection of $2-\left[{ }^{14} \mathrm{C}\right]$-deoxyglucose. Sham Op.: sham-operated group. $\mathrm{N}$ : number of animals. 
A
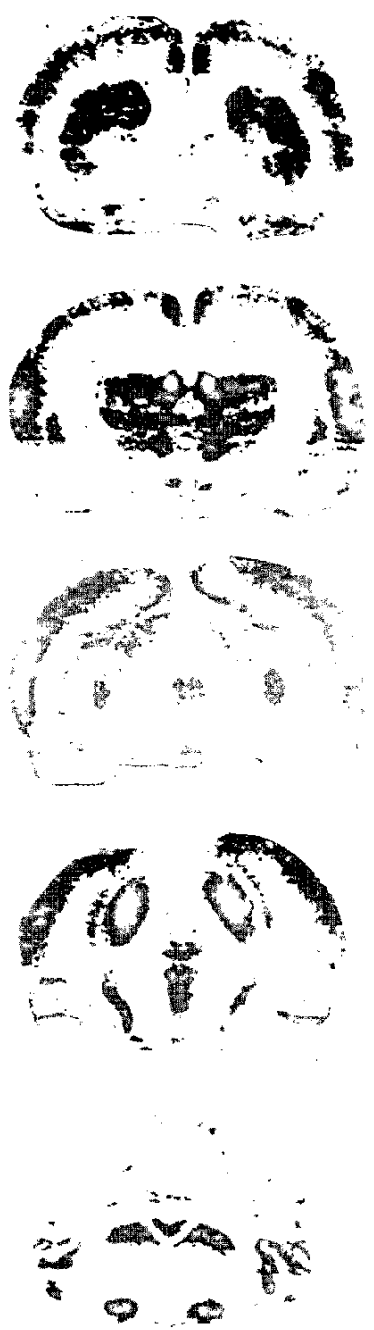

B
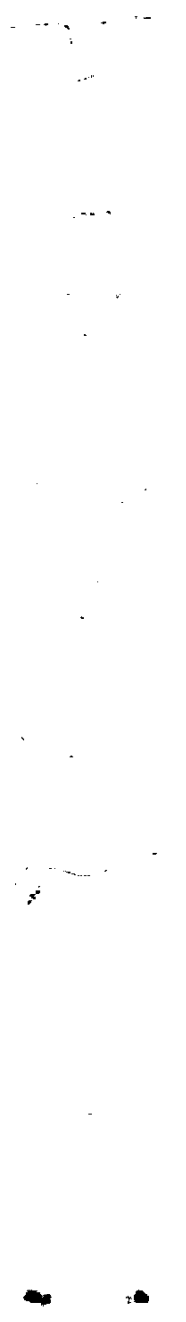

C

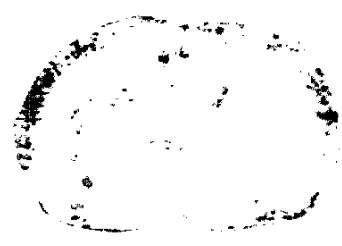

$\frac{E}{E}$

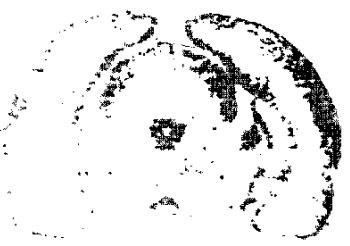

옹

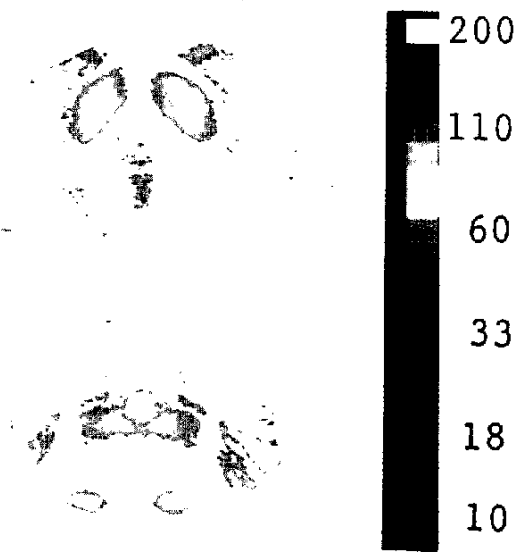

Fig. 1. Examples of image-processed autoradiograph of LCGU in sham-operated, ischemic control and SAM-treated rats. A: sham-operated animal, B: ischemic control animal, C: SAM-treated animal. The rate of LCGU is encoded in the color scale $(\mu \mathrm{mol} / 100 \mathrm{~g} / \mathrm{min})$. LCGU was measured at $24 \mathrm{hr}$ after recirculation following $30 \mathrm{~min}$ forebrain ischemia $(B, C$ ) or the sham operation ( $A$, see text). Note the lowered LCGU in the ischemic control animal and the relatively greater LCGU in SAM-treated animals compared with control animals.

have ameliorated LCGU values not only in the neurons but also in the glia cells, because SAM ameliorated LCGU values in many nuclei including the neuron-rich region (caudate nucleus and putamen) as well as glia cell-rich region (white matter).

Pulsinelli et al. (15) applied this method to the post-ischemic brain following forebrain ischemia for $30 \mathrm{~min}$ and demonstrated that the glucose utilization in the post-ischemic brain was, in general, depressed for up to 24 to $48 \mathrm{hr}$ in brain regions subjected to either moderate or severe ischemia. In the present study, the LCGI values were depressed in all 43 brain regions examined at $24 \mathrm{hr}$ after the forebrain ischemia for $30 \mathrm{~min}$. A greater de- 
Table 2. Effect of SAM upon reduced LUGU cerebral ischemia

\begin{tabular}{|c|c|c|c|c|c|}
\hline & $\begin{array}{l}\text { Sham-operated } \\
\text { group (4) }\end{array}$ & Control (6) & $\begin{array}{l}\text { Decrease } \\
\text { rate }(\%)^{\mathbf{a}}\end{array}$ & $\begin{array}{l}\text { SAM } \\
100 \times 6^{\mathrm{b}}(5)\end{array}$ & $\begin{array}{l}\text { Recovery } \\
\text { rate }(\%)^{a}\end{array}$ \\
\hline \multicolumn{6}{|l|}{ Cerebral Cortex } \\
\hline Frontal & $47.5 \pm 6.1$ & $25.4 \pm 3.0$ & 53.5 & $40.8 \pm 5.2^{*}$ & 85.9 \\
\hline Sensorimotor & $51.3 \pm 7.2$ & $26.0 \pm 3.6$ & 50.7 & $36.9 \pm 5.6$ & 71.9 \\
\hline Parietal & $57.8 \pm 4.3$ & $24.2 \pm 3.8$ & 41.9 & $37.7 \pm 5.1^{\#}$ & 65.2 \\
\hline Cingulate & $62.0 \pm 7.1$ & $31.2 \pm 4.9$ & 50.3 & $48.0 \pm 5.5^{*}$ & 77.4 \\
\hline Auditory & $71.4 \pm 4.3$ & $26.6 \pm 3.1$ & 37.3 & $41.1 \pm 8.0$ & 57.6 \\
\hline Visua! & $54.9 \pm 4.3$ & $23.3 \pm 3.6$ & 42.4 & $35.1 \pm 5.3^{\#}$ & 63.9 \\
\hline Piriform & $55.9 \pm 5.4$ & $38.9 \pm 2.9$ & 69.5 & $53.1 \pm 4.4^{*}$ & 95.0 \\
\hline N. Accumbens & $33.4 \pm 6.0$ & $20.4 \pm 2.8$ & 61.1 & $31.1 \pm 3.2^{*}$ & 93.1 \\
\hline Caudate-Putamen & $56.9 \pm 10.4$ & $28.2 \pm 2.1$ & 49.5 & $45.7 \pm 5.3^{*}$ & 80.3 \\
\hline Globus Pa!lidus & $29.7 \pm 5.5$ & $18.2 \pm 3.0$ & 61.3 & $24.8 \pm 2.4$ & 83.5 \\
\hline Lateral Septal N. & $31.9 \pm 9.0$ & $14.3 \pm 1.9$ & 44.8 & $26.3 \pm 3.7^{* *}$ & 82.4 \\
\hline \multicolumn{6}{|l|}{ Hypothalamus } \\
\hline Lateral N. & $42.2 \pm 4.6$ & $23.2 \pm 4.7$ & 55.0 & $32.9 \pm 3.4$ & 78.0 \\
\hline Mamillary Body & $74.3 \pm 7.2$ & $52.7 \pm 6.7$ & 70.9 & $72.4 \pm 7.5^{\#}$ & 97.4 \\
\hline \multicolumn{6}{|l|}{ Thalamus } \\
\hline Lateral N. & $56.0 \pm 6.4$ & $27.8 \pm 4.0$ & 49.6 & $43.5 \pm 5.2^{*}$ & 77.7 \\
\hline Dorsomedial $N$. & $57.6 \pm 6.1$ & $32.5 \pm 5.4$ & 56.4 & $48.8 \pm 5.7^{\#}$ & 84.7 \\
\hline Ventral N. & $56.2 \pm 5.8$ & $23.6 \pm 4.2$ & 42.0 & $40.7 \pm 7.2^{\#}$ & 72.4 \\
\hline Lateral Geniculate N. & $49.7 \pm 4.9$ & $24.1 \pm 4.4$ & 48.5 & $39.5 \pm 3.3^{*}$ & 79.5 \\
\hline Medial Geniculate N. & $61.7 \pm 8.7$ & $25.3 \pm 4.3$ & 41.0 & $45.2 \pm 5.5^{* *}$ & 73.3 \\
\hline Lateral Habenular N. & $79.4 \pm 13.6$ & $47.1 \pm 6.4$ & 59.3 & $72.1 \pm 6.6^{*}$ & 90.8 \\
\hline Subthalamic N. & $56.8 \pm 3.8$ & $35.4 \pm 5.2$ & 62.3 & $54.2 \pm 7.1^{\#}$ & 95.4 \\
\hline Amygdala Tomplex & $37.5 \pm 4.4$ & $18.1 \pm 3.9$ & 48.3 & $27.8 \pm 3.7$ & 74.1 \\
\hline \multicolumn{6}{|l|}{ Hippocampus } \\
\hline CAl & $45.5 \pm 6.9$ & $26.7 \pm 6.2$ & 58.7 & $41.2 \pm 5.9 \#$ & 90.5 \\
\hline Ventral & $41.6 \pm 5.3$ & $18.8 \pm 4.8$ & 45.2 & $29.1 \pm 4.7$ & 70.0 \\
\hline Dentate Gyrus & $55.6 \pm 5.8$ & $33.0 \pm 5.3$ & 59.3 & $49.6 \pm 7.8$ & 89.2 \\
\hline Interpedunclar N. & $79.7 \pm 8.0$ & $52.5 \pm 7.8$ & 65.9 & $74.4 \pm 6.8^{\#}$ & 93.4 \\
\hline S. Nigra Compacta & $39.5 \pm 6.7$ & $25.6 \pm 3.9$ & 64.8 & $39.0 \pm 4.1^{*}$ & 98.7 \\
\hline S. Nigra Reticulata & $33.8 \pm 5.5$ & $20.3 \pm 3.9$ & 60.0 & $32.7 \pm 3.4^{*}$ & 96.7 \\
\hline V. Tegmental Area & $37.3 \pm 5.7$ & $22.1 \pm 3.7$ & 59.2 & $36.9 \pm 5.1^{*}$ & 98.9 \\
\hline Red $N$ & $40.9 \pm 5.9$ & $29.6 \pm 4.3$ & 72.4 & $43.8 \pm 7.0$ & 107.1 \\
\hline Superior Colliculus & $46.8 \pm 3.0$ & $28.6 \pm 4.1$ & 61.1 & $46.4 \pm 6.1^{*}$ & 99.1 \\
\hline Inferior Colliculus & $108.9 \pm 3.7$ & $73.6 \pm 7.0$ & 67.6 & $104.8 \pm 5.8^{* * *}$ & 96.2 \\
\hline Pontine R.F. & $31.1=5.3$ & $18.7 \pm 3.2$ & 60.1 & $33.3 \pm 2.7^{* * *}$ & 107.1 \\
\hline Dorsal Raphe N. & $39.8 \pm 6.2$ & $21.7 \pm 3.6$ & 54.5 & $36.8 \pm 4.7^{*}$ & 92.5 \\
\hline Locus Coeruleus & $45.9 \pm 8.4$ & $24.3 \pm 4.7$ & 52.9 & $42.4 \pm 5.9^{*}$ & 92.4 \\
\hline Superior Olieves & $101.0 \pm 8.8$ & $68.2 \pm 6.4$ & 67.5 & $108.9 \pm 8.2^{* * *}$ & 107.8 \\
\hline Cochlear N. & $94.0 \pm 5.2$ & $69.0 \pm 7.7$ & 73.4 & $98.5 \pm 6.8^{*}$ & 104.8 \\
\hline Vestibular N. & $70.9 \pm 4.6$ & $50.4 \pm 6.0$ & 71.1 & $82.4 \pm 4.7^{* * *}$ & 116.2 \\
\hline \multicolumn{6}{|l|}{ Cerebelium } \\
\hline Cortex & $30.3 \pm 3.6$ & $17.6 \pm 3.5$ & 58.1 & $31.4 \pm 3.1^{* *}$ & 103.6 \\
\hline Dentate $\mathrm{N}$. & $56.0 \pm 4.9$ & $33.2 \pm 6.5$ & 59.3 & $60.8 \pm 5.1^{* *}$ & 108.6 \\
\hline White Matter & $14.6 \pm 5.4$ & $3.7 \pm 1.5$ & 25.3 & $10.9 \pm 1.3^{* * *}$ & 74.7 \\
\hline \multicolumn{6}{|l|}{ Neuronal Fiber } \\
\hline Corpus Callosum & $13.9 \pm 4.4$ & $6.3 \pm 1.6$ & 45.3 & $11.3 \pm 1.5^{\#}$ & 81.3 \\
\hline Interna! Capsule & $1.2 .2 \pm 2.9$ & $6.0 \pm 1.8$ & 49.2 & $10.1 \pm 1.7$ & 82.8 \\
\hline Lateral Lemniscus & $30.9 \pm 3.2$ & $16.4 \pm 2.7$ & 53.1 & $25.5 \pm 4.1^{\#}$ & 82.5 \\
\hline
\end{tabular}

Vaiues represent the mean \pm S.F.M. $(\mu \mathrm{mol} / 100 \mathrm{~g} / \mathrm{min})$. The number of animals is shown in parentheses. a \% changes from the sham-operated group. b SAM was administered (i.p.) every 1 hr for 6 times from the recirculation following $30 \mathrm{~min}$ forebrain ischemia. Statistically different from the control (Student's t-test) : $P<0.1$ (*) $^{*} P<0.01$ ( $\left.^{*}\right), P<0.02$ ( *) $^{*}$ and $P<0.01\left(^{* *}\right)$. 
crease was observed in the forebrain structures than in the midbrain. pons and the medulla. These results coincided well with those described by Pulsinelli et al. (15).

The reduced LCGU values were ameliorated by SAM by $35-195 \%$ in all 43 brain regions examined and particularly those in 24 regions were significantly improved. In SAMtreated animals, the rates of LCGU were increased significantly up to more than $75 \%$ of the rate in the sham-operated group in the forebrain structures including the cerebral cortices, caudate-putamen, thalamic nuclei and some other nuclei. Although not significantly in the hippocampus, the LCGU values were improved up to approx. $90 \%$ of the value in the sham-operated group. Furthermore. the LCGU values in most structures in the midbrain and hindbrain such as the substantia nigra, colliculi, pontine reticular formation and cerebellum, where the reduction in the LCGU was less than those in the forebrain structures. were recovered to a level nearly the same as that in the sham-operated group. Thus it is clear that SAM ameliorated the reduced LCGU caused by the ischemia in numerous brain structures.

Although the mechanism of the beneficial effect of SAM remained unclear from the present study, the following possibilities can be considered. Since the physiological variables (Table 1) in SAM-treated animals were not significantly different from those in control animals, the ameliorating effect of SAM in the LCGU was not elicited by changes in these variables. Although LCGU values are known to be increased during epilepsy (22), no seizures were observed in animals treated with SAM. This indicates that the ameliorating effect of SAM was not produced by epileptogenesis. The fact that SAM did not produce any changes in spontaneous EEG (23) supports the view that SAM does not produce any seizures.

It has been well-known that respiratory function in mitochondria was impaired after the ischemia (24) presumably by activation of phospholipase $C$ or $A_{2}$ due to increased intracellular $\mathrm{Ca}$ concentration following the ischemia (25). SAM was reported to suppress mitochondrial swelling induced by $\mathrm{Ca}$ or phospholipase $A_{2}$ and to inhibit phos- pholipase $A_{2}$ directly $(26,27)$. Thus it is possible that SAM protects mitochondria from the ischemia. This possibility was supported by the fact that SAM prevented ATP content from decreasing without increasing the lactate content in the ischemic brain $(8,9)$. This indicates that SAM maintains energy synthesis in the ischemic brain by protecting the mitochondria from ischemia (9). Since the brain exclusively uses glucose to synthesize ATP, the improving effect of SAM on the LCGU could result from the protection of mitochondria from ischemia.

On the other hand. Sato et al. recently found that repeatedly administered SAM prevented CAl neurons in the hippocampus from ischemia-induced delayed death by activation of transmethylation of the membrane by using SAM as a methyl donor (11). Since CAl neurons of the hippocampus are selectively vulnerable, delayed neuronal death are particularly observed in this region. Transmethylation of the neuronal membrane, however, could be activated by SAM not only in the CAI neurons but in all neurons in the brain. Thus, the ameliorating effects of SAM against the reduced $L C G U$ could be elicited by the protection of neuronal membranes through activation of transmethylation in the cerebral parenchyma, which in turn increased LCGU in numerous brain structures.

The other possible mechanism is that SAM increased reduced local cerebral blood flow and prevented neurons from ischemic dam. ages, because SAM is known to increase erythrocyte deformability (28) and ameliorate hypoperfusion following the ischemia ( $K$. Kobayashi et al., unpublished observation).

SAM used in the present experiment contained mannitol as a filler $(38.5 \%, \mathrm{w} / \mathrm{w})$. besides $S$-adenosyl-L-methionine-2-sulfate tosylate $(61.5 \%, W / W)$. It has been found that $\mathrm{S}$-adenosyl-L-methionine itself or its sulfate tosylate salt protected the $\mathrm{CAl}$ neuron from the delayed neuronal death $(10,11)$. In addition, SAM containing mannitol increased the reduced ATP content significantly in the ischemic brain compared with ischemic control animals treated with vehicle containing mannitol (9). These data suggested that SAM. but not mannitol, had beneficial effects. Thus it may be feasible to say that the ameliorating 
effect of SAM on the LCGU is solely due to Sadenosyl-L-methionine and not mentol, although the effects of mannitol were not determined in the present study.

Acknowledgments: The authors wish to express their deep gratitude to Dr. L. Sokoloff for kindly teaching us the technimue for calculating the LCGU.

\section{References}

? Raichle, M.E.: The pathophysiology of brain ischemia. Ann. Neurol. 13, 2-10 (1983)

2 lijima, S., Hara, K., Suga, H., Nakamura, S. and Kameyama, M.: Effects of ischemia on hydroxylase cofactor (tetrahydrobiopterin! and monoamine neurotransmitters in the rat brain. Stroke 17. 529-533 (1986)

3 Hirata, F. and Axelrod, J.: Enzymatic methylation of phosphotidylethanolamine increase erythrocyte membrane fluidity. Nature 275, 219 $220(1978)$

4 Ishikawa, T., Sakabe, T., Nishiyama, Y., Abe, M., Takeshita, H., Niwa, M. and Ozaki, M.: Effects of $\mathrm{S}$-adenosyl-L-methionine on cerebral monoamine turnover after hypoxia in rats. Folia Pharmacol. Japon. 88, 425-43! (1986) (Abs. in English)

5 Strittmatter, W.J., Hirata, F. and Axelrod, J.: Increase Ca-ATPase activity associated with methylation of phospholipids in human erythrocytes. Biochem. Biophys. Res. Commun. 88, 147-153 (1979)

6 Fiecchi, A.: U.S. Patent No. 3.954, May (1976)

7 Kozuka, M., Kubo, Y., Kobayashi, K. and Iwata, $\mathrm{N}$.: Effects of $S$-adenosyl-L-methionine upon ischemia-induced brain edema in the Mongolian gerbils and spontaneously hypertensive rats. Japan. J. Pharmacol. 46, 225-226 (1988)

8 Kozuka, M. and Iwata, N.: S-Adenosyl-!_methionine ameliorates ischemic brain metabolism in spontaneously hypertensive rats. Japan. J. Pharmacol. 49, 173-179 (1989)

9 Katayama, Y., Shimizu, J., Memezawa, H., Minamisawa, H., Imamura, K, Mizoguchi, M., Sugimoto, S., Nagazumi, A. and Terashi, A.: Effects of $S$-adenosyl-L-methionine on experimental cerebral ischemia. Brain Nerve 37, 243247 (1985) (Abs. in English)

10 Matsui, Y., Kubo, Y. and Iwata, N.: S-AdenosylL-methionine prevents ischemic neuronal death. Eur. J. Pharmacol. 144, 211-216 (1987)

11 Sato, H., Hariyama, H. and Moriguchi, K.: SAdenosyl-L-methionine protects the hippocampal CAl neurons from the ischemic neuronal death in rat. Biochem. Biophys. Res. Commun. $150,491-496(1988)$
12 Moriguchi, K., Horita, I., Hariyama, H., Ushijima, $T$. and Nakano, M.: The effects of S-adenosylL-methionine sulfate tosylate (FO-1561) on survival time in various brain damage models. Brain Nerve 40, 351-356 (1988) (Abs. in English)

13 Yoshimizu, N. and Hiramoto, S.: Clinical evaluation of $\mathrm{S}$-adenosyl-L-methionine (SAMe) in cerebrovascular diseases. Clin. Rep. 21, 415430 (1987) (in Japanese)

14 Sokoloff, L., Reivich, M., Kennedy, C., Des Rosiers, M.H., Patlak, C.S., Pettigrew, K.D., Sakurada, O. and Shinohara, M.: The $\left[{ }^{14} \mathrm{C}\right]$ deoxyglucose miethod for the measurement of local cerebral glucose utilization: theory, procedure and normal values in the conscious and subanesthetized albino rat. J. Neurochem. 28, $897-916$ (1977)

15 Pulsinelli, W.A., Levy, D.E. and Duffy, T.E.: Regional cerebrál blood flow and glucose metabolism following transient forebrain ischemia. Ann. Neurol. 11, 499-509 (1982)

16 Pulsinelli, W.A. and Brierley, J.B.: A new model of bilateral hemispheric ischemia in the unanesthetized rat. Stroke 10, 267-272 (1979)

17 Nakajima, E., Yasukawa, Y., Shinozaki, H., Matsubara, Y., Fujisita, S. and Okano, S. Quantitative method for whole body autoradiography and application to tissue distribution study of FO-1561 in rats. Xenobiol. Metab. Dispos. 3, 67-80 (1988) (Abs. in English)

18 Stramentinoli, G. and Catto, E.: Pharmacokinetic studies of $S$-adenosyl-L-methionine (SAMe) in several animal species. Pharmacol. Res. Commun. 8, 211-218 (1976)

19 Stramentinoli, G., Gualano, M. and Galli-Kienle, $M$.: Intestinal absorption of $\mathrm{S}$-adenosyl- Lmethionine. J. Pharmacol. Exp. Ther. 209, 323326 (1979)

20 Wallenstein, S., Zucker, C.L. and Fleiss, J.L.: Some statistical methods useful in circulation research. Circ. Res. 47, 1-9 (1980)

21 Hatazawa, J., Ito, M., Matsuzawa, T., Ido, T. and Watanuki, S.: Measurement of the rates of cerebral oxygen consumption to glucose utilization by positron emission tomography: Its consistency with the values determined by the Kety-Schmidt method in normal volunteers. 1. Cereb. Blood Flow Metab. 8, 426-432 (1988)

22 Duncan, G.E, Stumpf, W.E. and Pilgrim, C.: Cerebral metabolic mapping at the cellular level with dry-mount autoradiography of $\left[{ }^{3} \mathrm{H}\right] 2$ deoxyglucose. Brain Res. 401, 43-49 (1987)

23 Suzuki, J., Nakamoto, Y. and Shinkawa, Y.: Local cerebral glucose utilization in epileptic 